\title{
Analysis of Hierarchical Incentives of Human Error in Ship Collision Based on ISM Model
}

\author{
Qiuxia Yang \\ College of Transport \& Communications \\ Shanghai Maritime University \\ Shanghai, China 201306
}

\begin{abstract}
According to statistics, the number of accidents caused by human error accounts for $80 \%$ of the total number of accidents. Based on the type of collision accident, the passage analyzes the human factors which caused human error, the purpose is to find out the level of the logical relationship between incentives. It adopts the interpretation structure model (ISM) method, selects 10 common human factors in the collision accident, constructs adjacency matrix, calculates the reachable matrix and divides level classification, level 7 pass structure model is obtained. The model is analyzed from four levels: surface factor, shallow factor, middle factor and deep factor. The result shows that the most profound human factors of human error caused by ship collision are crew fatigue and lacking of training.
\end{abstract}

Keywords-collision; human error; ISM; hierarchical incentives

\section{INTRODUCTION}

Maritime transportation is the main artery in the field of transportation of China, which has a strong role in promoting the development national economy and trade. With the increase of maritime transport, the frequency of maritime accidents also increases. According to statistics, during 2016 285 the total number of water traffic accidents, maritime accidents are divided into collision and grounding accident, rock accident, touch damage accident, fire explosion accident, sinking accident, anchor and other accidents, in which the majority with collision accidents. The occurrence of maritime accidents is closely related to human, ship, environment, organization and management, and $80 \%$ of maritime accidents are related to human factors. The marine accidents caused by human error will not only endanger the life of crew, but also bring great economic loss, and even affect the ecological environment of the sea.

\section{RESEARCH STATUS}

Nowadays, the domestic and foreign scholars have focused on the "human error" of ship collision accident, Fu Yuhui [1] thinks that the cause of human error of the collision is one's own limitations and outside influence. The former includes information processing ability, physical condition, skills and knowledge, while the latter includes environmental characteristics, work tasks and man-machine access. Li Lingling and Qiu Lei [2] models by using the method of association rule, and analyzes the cause on the factors of human error, thinks that environmental factors and human factors are important factors leading to a collision occurs. Liang Kailin[3] traces analysis ship collision accident by GREAM method, from the perspective of human cognitive behavior process, quantitative prediction to ship collision accident, computes the probability of human error, in order to take corresponding measures. Zhang Lili et al.[4] established a game model composed of the government, shipping enterprises and crew to explore the causes of human maritime accidents. CATHERINE $\mathrm{H}$ et al. [5]believe that $70 \%$ of maritime accidents are caused by people's cognitive error, which are also related to the sleep, mental and physical conditions of sailors. EMESTOS $\mathrm{T}$ [6]studied the relationship between specific accident types and human element composition, and pointed out that the occurrence of ship collision accidents was closely related to the captain. CHRISTINE C [7]pointed out that mistakes in coordination and communication between crew could lead to ship collision accidents. CHRISTINE $\mathrm{C}$ et al.[8]proposed an improved modified HFACS-Coll model by analyzing 27 ship collision accidents, and pointed out that human error was related to leading organizations and individual behaviors. Muhammad and Ingrid [9] analyzed the accident through the method of cognitive reliability and error analysis (CREAM), believing that ship collision is closely related to human fatigue.

Existing scholars construct model by different quantitative methods, or to take direct qualitative analysis method, state that the error factors which leads to people, but there is no incentive for people error factors in shallow, middle and deep division of different levels, if we divide the influence factors to different levels of hierarchy, so, to ship collision accident caused by people error, we have the same points to prevent the accident from different angles, to achieve better target to control the accident.

\section{CONSTRUCTION OF ISM MODEL OF HUMAN ERROR INDUCING FACTOR IN SHIP COLLISION}

ISM, called interpretation structure model, a complex diverse elements of the system can be decomposed into several simple sub-systems, with relevant experience and computer auxiliary, will form a multilevel recursive structure model, a difficult view to clarify can transform into intuitive 
structure model with qualitative methods. On the basis of ISM, the passage merges sort to this kind of collision accident, analyzes the causes of human error, builds multistage structural model, level analysis was carried out on the cause, cause analysis of this article not only has a certain reference role for maritime safety regulations formulation, but also act as a reference to intervention for maritime security.

\section{A. Set the Key Issues and Select Causing Factors}

Induction of human error factors have a lot of aspects, involving people, equipment, environment, organization and management, the text only from the perspective of human factors, sees the human factors as a system $\mathrm{H}$, in many cases of maritime accidents, has established the following ten people factors $\mathrm{H} 1 \sim \mathrm{H} 10$, specific as follows:

- H1: Communication and information exchange are insufficient between crew

Communication and information exchange is a way to understand the intentions and behaviors of others and promote teamwork. Communication includes downward communication such as captain's instructions, issuance of documents and verbal warnings, and upward communication of basic crew members to their superiors. If communication is divided between crew, it can't very well between departments, between groups to work together, once appear, communication is not smooth, the phenomenon such as information transmission error, will cause the ship real-time information transmission error and lag, so crew should keep effective and right between real-time contact, avoid to bring decision-making errors, reduce the number of maritime accidents from happening.

\section{- H2: Dereliction of duty of watch-keepers}

Watch-keepers are one of the important positions in ship navigation. The duty officer should hold a telescope, carefully observe the surrounding sea conditions, and report special situations to the superior at any time. Many of collision accidents because of leaving jobs, busying with other things, distracting, without the proper use of equipment to carry on the outlook, etc., and even some lookout, the ship did not arrange this situation, will also bring risks to the maritime accidents. Especially in the case of heavy traffic, it is necessary to consider that many people are on duty together in order to avoid the collision of ships.

\section{- H3: Crew fatigue due to lack of sleep}

At present, there are not a few collision accidents caused by the fatigue driving of crew, and serious accident consequences are caused. During the driving process, the driver may experience intermittent drowsiness due to the long sailing time. Especially at night, the driver must be highly alert. Crew should be provided with a strict schedule for rest, and the sleep time of crew should not be reduced due to excessive work load, but more staff should be provided. Sea is a long time of transport process, especially the ocean sailing schedule, long working condition is easy to cause the crew fatigue and poor mental pressure, so you have to arrange reasonable shift system and the strict schedule.

\section{- H4: Crew lack of technical proficiency}

In terms of the lack of technical level, crew is not fully familiar with the use of navigation instruments, radar, etc., or is not in use, which is a very big hidden danger for maritime navigation. In the case of bad sea conditions, it is necessary to have a skilled crew to operate the ship to minimize the danger. As a qualified seafarer, he should fully master navigation skills and technology, and have the ability to solve emergencies.

\section{- H5: Crew show abnormal physical function}

Physical function refers to the life activities of the whole human body, organs and systems. In the analysis of several collision accidents, the two main factors are the excess body alcohol concentration and poor physical quality of crew. Under a great deal of working pressure, many crew will use alcohol for mental replenishment, but alcohol can easily damage people's nervous system and disrupt their working and mental states. Due to poor supervision and disregard of regulations, there are still a few crew who are mentally ill and unable to concentrate on their duty due to drinking on board. Some crew in the face of long voyage will appear the symptom such as low blood pressure, poor physical quality will affect the whole team performance measures, the crew of the body function is very important for maritime navigation safety.

\section{- H6: Crew's mental quality is not good enough}

Higher negative emotions crew work hard to face suddenly appeared in the navigational hazards, to the poor communication skills, such as anxiety, terror, worry, fear, despair, and so on, the mood is easy to affect the choice of the crew, and limit the ability of doing things. In addition, overconfidence and overheated brain will also affect people's mental state and lead to human decision-making mistakes. Maritime navigation needs to have a high degree of psychological quality to deal with irregular dangerous situations, so as to reduce the occurrence of maritime accidents.

\section{- H7: Crew lack of knowledge and ability}

People's education degree determines their knowledge level, and the level of knowledge will affect their error rate in work. In terms of lack of knowledge level, some crew appear surveying error and wrong calculation, and no real time monitoring collision developments, lead to survey two ship relative position errors, so the report to VTS also can appear error. Sailors with higher level of knowledge attach more importance to navigation safety and attach more importance to collision avoidance rules. Only with sufficient knowledge can the seafarers make a correct risk assessment of the dangerous situation at sea and make the most prompt corrective measures for maritime accidents.

\section{- H8: Crew error on the operation}

Mistakes in crew operations include wrong operations and careless operations. Careless operation can be vigilant and supervised in the follow-up training process, but in the case analysis of many maritime accidents, many crew have 
wrong use of equipment and equipment. For example, wrong use of the safety alarm device, when the danger occurred, crew did not immediately inform all crew; Incorrect use of navigation equipment results in signal deviation and indication error. Error in crew's operation behavior is a serious and alarming thing in the course of navigation, which will lead to the loss of control of the ship and easily lead to ship accidents.

\section{- H9: Crew lack of relevant training}

For the training of staff, it is not only the cultivation of personal ability, but also the efficient management of the team. Managers should organize regular crew training, such as knowledge level, individual anti-pressure ability, team communication ability, emergency contingency ability and so on. A good training system can reduce the cognitive inertia of crew, as well as the attention to work that is not usually taken seriously. Enhance how to avoid collision efficiently and gradually carry out the education work that may result from ship collision.
- H10: Crew do not observe international rules for preventing collisions at sea

The international rules for preventing collisions at sea is a maritime traffic regulation formulated by the IMO (international maritime organization) to prevent and avoid collision between ships at sea. After reading collision accident cases, more appearing is not following the correct outlook rules, using accurately radar, appearing ignore to ships, thinking that he will avoid and without active measures to avoid and so on. In order to reduce the occurrence of collision accidents caused by human error, the crew should strictly observe the international rules for preventing collision at sea.

\section{B. The Correlation Between Induction Factors}

Human factors constitute system $\mathrm{H}, \mathrm{H}=\left\{\mathrm{H}_{1}, \mathrm{H} 2 \ldots, \mathrm{H}_{10}\right\}$, from the above analysis, the directed graph of human factor system $\mathrm{H}$ can be obtained, as shown in "Fig. 1".

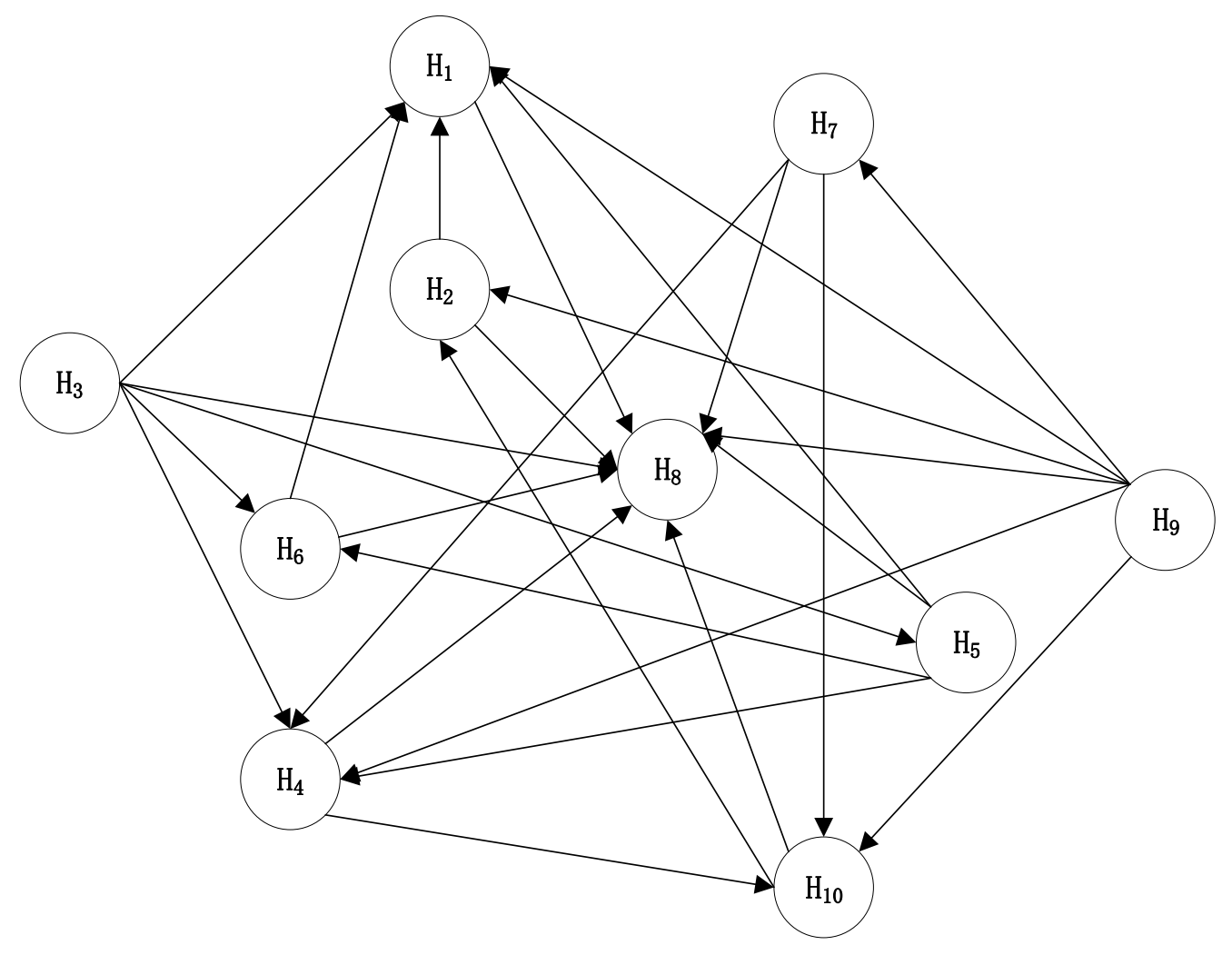

Fig. 1. Directed graph of human error system in ship collision.

\section{Set up the Adjacency Matrix}

The adjacency matrix can be used to represent the relationship between directed graphs. According to the system directed graph in figure 1, the adjacency matrix A is established, where the element aij is defined as follows:

$$
\begin{array}{r}
1, \\
\text { Aij }=\left\{\begin{array}{l}
\text { When Hi has effects on } \mathrm{Hj} \\
0,
\end{array} \text { When Hi has no effect on } \mathrm{Hj}\right.
\end{array}
$$

Based on the relationship between $\mathrm{H} 1$ and $\mathrm{H} 10$, the adjacency matrix $\mathrm{A}$ is: 


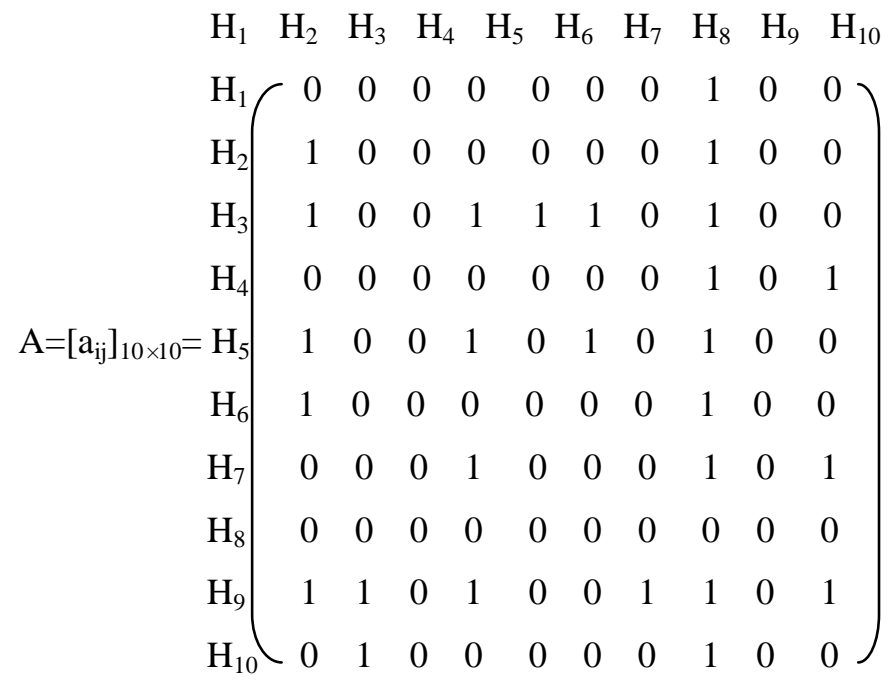

\section{Set up the Reachable Matrix}

Reachable matrix describes the reach extent through a certain length of path in the directed graph between each node in the form of a matrix, shows the structure of direct and indirect relations between the elements. According to the operational rule of the Boolean matrix, $(0+0=0,0+1=1$, $1+0=1,1+1=1,0 \times 0=0,0 \times 1=0,1 \times 0=0,1 \times 1=1)$, adjacent matrix adds unit matrix I then multiplies by itself, to all the products are equal on the kth power, now the $(\mathrm{A}+\mathrm{I}) \mathrm{k}$ is reachable matrix that was calculated. The calculation formula of transformation of adjacency matrix into reachable matrix is as follows: $(\mathrm{A}+\mathrm{I}) \neq(\mathrm{A}+\mathrm{I})^{2} \neq \ldots \neq(\mathrm{A}+\mathrm{I}) \mathrm{k}=$ $(\mathrm{A}+\mathrm{I}) \mathrm{k}+1(\mathrm{k} \leq \mathrm{n}-1)$, so the reachable matrix is $\mathrm{B}=(\mathrm{A}+\mathrm{I}) \mathrm{k}$.

According to the adjacent matrix, we can get the reachable matrix B through calculating by MATLAB.

MATLAB commands to calculate the reachable matrix B are as follows:

$$
\begin{aligned}
& \mathrm{n}=\operatorname{size}(\mathrm{A}, 1) ; \\
& \mathrm{B}=\mathrm{A} ; \\
& \text { for } \mathrm{i}=2: \mathrm{n} \\
& \mathrm{B}=\mathrm{B}+\mathrm{A}^{\wedge} \mathrm{i} ; \\
& \text { End } \\
& \mathrm{x}=\operatorname{eye}(\mathrm{n}, \mathrm{n}) ; \\
& \mathrm{B}=\mathrm{B}+\mathrm{x} ; \\
& \mathrm{B}(\mathrm{B} \sim=0)=1 ;
\end{aligned}
$$

The following reachable matrix $\mathrm{B}$ is obtained, where element 1 represents that the elements of the row have direct or indirect binary relations to column elements, while element 0 indicates that there is no.

$$
\mathrm{B}=\left(\begin{array}{llllllllll}
1 & 0 & 0 & 0 & 0 & 0 & 0 & 1 & 0 & 0 \\
1 & 1 & 0 & 0 & 0 & 0 & 0 & 1 & 0 & 0 \\
1 & 1 & 1 & 1 & 1 & 1 & 0 & 1 & 0 & 1 \\
1 & 1 & 0 & 1 & 0 & 0 & 0 & 1 & 0 & 1 \\
1 & 1 & 0 & 1 & 1 & 1 & 0 & 1 & 0 & 1 \\
1 & 0 & 0 & 0 & 0 & 1 & 0 & 1 & 0 & 0 \\
1 & 1 & 0 & 1 & 0 & 0 & 1 & 1 & 0 & 1 \\
0 & 0 & 0 & 0 & 0 & 0 & 0 & 1 & 0 & 0 \\
1 & 1 & 0 & 1 & 0 & 0 & 1 & 1 & 1 & 1 \\
1 & 1 & 0 & 0 & 0 & 0 & 0 & 1 & 0 & 1
\end{array}\right)
$$

\section{E. Divide into Different Levels Between Factors}

Hierarchical division refers to the division of accessibility matrix as the benchmark, into different levels. In the reachable matrix, according to their different positions in the system, the elements can be divided into reachable sets $\mathrm{R}(\mathrm{Hi})$ and advanced sets $\mathrm{A}(\mathrm{Hi})$, reachable sets $\mathrm{R}(\mathrm{Hi})$ refers to the set of all elements that can be reached from $\mathrm{Hi}$, that is, in the reachable matrix, the entire set of column elements whose row $\mathrm{i}$ is shown as $1, \mathrm{R}(\mathrm{Hi})=\{\mathrm{Hj} \in \mathrm{H} \mid \mathrm{aij}=1\}$. The advanced set $\mathrm{A}(\mathrm{Hi})$ refers to the set of all the elements that can reach $\mathrm{Hi}$, that is, in the reachable matrix, the entire set of row elements whose column $\mathrm{j}$ is shown as $1, \mathrm{~A}(\mathrm{Hi})=\{\mathrm{Hj} \in$ $\mathrm{H} \mid \mathrm{aij}=1\}$. The superlative element $\mathrm{T}(\mathrm{Hi})$ refers to the set of elements that cannot reach other elements except themselves. According to $\mathrm{T}(\mathrm{Hi})=\{\mathrm{Hj} \in \mathrm{H} \mid \mathrm{R}(\mathrm{Hi}) \cap \mathrm{A}(\mathrm{Hi})=\mathrm{R}(\mathrm{Hi})\}$, the highest $\mathrm{T}(\mathrm{Hi})$ can be obtained. First, the superlative element is obtained, the corresponding row and column are crossed out in the reachable matrix, and the sub-advanced element is obtained by the same steps from the remaining reachable matrix, so as to divide the hierarchical levels. If you use $\mathrm{L} 1, \mathrm{~L} 2, \ldots, \mathrm{Lk}(\mathrm{k} \leq \mathrm{n}) \quad(\mathrm{k} \leq \mathrm{n})$ represents the level from top to bottom, then there are $\mathrm{k}$ levels of the system, which can be expressed in the following formula: $\mathrm{L}(\mathrm{k})=[\mathrm{L} 1, \mathrm{~L} 2, \ldots, \mathrm{Lk}]$. 
According to $\mathrm{T}(\mathrm{Hi})=\{\mathrm{Hj} \in \mathrm{H} \mid \mathrm{R}(\mathrm{Hi}) \cap \mathrm{A}(\mathrm{Hi})=\mathrm{R}(\mathrm{Hi})\}$, the top-level element at level 1 can be obtained from "Table I", $\mathrm{L} 1=\{\mathrm{H} 8\}$.

TABLE I. TOP-LEVEL ELEMENT AT LEVEL 1

\begin{tabular}{|l|l|l|l|}
\hline $\mathrm{H}_{\mathrm{i}}$ & $\mathrm{R}\left(\mathrm{H}_{\mathrm{i}}\right)$ & $\mathrm{A}\left(\mathrm{H}_{\mathrm{i}}\right)$ & $\mathrm{R}\left(\mathrm{H}_{\mathrm{i}}\right) \cap \mathrm{A}\left(\mathrm{H}_{\mathrm{i}}\right)$ \\
\hline $\mathrm{H}_{1}$ & 1,8 & $1,2,3,4,5,6,7,9,10$ & 1 \\
\hline $\mathrm{H}_{2}$ & $1,2,8$ & $2,3,4,5,7,9,10$ & 2 \\
\hline $\mathrm{H}_{3}$ & $1,2,3,4,5,6,8,10$ & 3 & 3 \\
\hline $\mathrm{H}_{4}$ & $1,2,4,8,10$ & $3,4,5,7,9$ & 4 \\
\hline $\mathrm{H}_{5}$ & $1,2,4,5,6,8,10$ & 3,5 & 5 \\
\hline $\mathrm{H}_{6}$ & $1,6,8$ & $3,5,6$ & 6 \\
\hline $\mathrm{H}_{7}$ & $1,2,4,7,8,10$ & 7,9 & 7 \\
\hline $\mathrm{H} 8$ & 8 & $1,2,3,4,5,6,7,8,9,10$ & 8 \\
\hline $\mathrm{H}_{9}$ & $1,2,4,7,8,9,10$ & 9 & 9 \\
\hline $\mathrm{H}_{10}$ & $1,2,8,10$ & $3,4,5,7,9,10$ & 10 \\
\hline
\end{tabular}

The top-level element at level 2 can be obtained from "Table II", L2=\{H1 $\}$

TABLE II. TOP-LEVEL ELEMENT AT LEVEL 2

\begin{tabular}{|l|l|l|l|}
\hline $\mathrm{H}_{\mathrm{i}}$ & $\mathrm{R}\left(\mathrm{H}_{\mathrm{i}}\right)$ & $\mathrm{A}\left(\mathrm{H}_{\mathrm{i}}\right)$ & $\mathrm{R}\left(\mathrm{H}_{\mathrm{i}}\right) \cap \mathrm{A}\left(\mathrm{H}_{\mathrm{i}}\right)$ \\
\hline $\mathrm{H}_{1}$ & 1 & $1,2,3,4,5,6,7,9,10$ & 1 \\
\hline $\mathrm{H}_{2}$ & 1,2 & $2,3,4,5,7,9,10$ & 2 \\
\hline $\mathrm{H}_{3}$ & $1,2,3,4,5,6,10$ & 3 & 3 \\
\hline $\mathrm{H}_{4}$ & $1,2,4,10$ & $3,4,5,7,9$ & 4 \\
\hline $\mathrm{H}_{5}$ & $1,2,4,5,6,10$ & 3,5 & 5 \\
\hline $\mathrm{H}_{6}$ & 1,6 & $3,5,6$ & 6 \\
\hline $\mathrm{H}_{7}$ & $1,2,4,7,10$ & 7,9 & 7 \\
\hline $\mathrm{H}_{9}$ & $1,2,4,7,9,10$ & 9 & 9 \\
\hline $\mathrm{H}_{10}$ & $1,2,10$ & $3,4,5,7,9,10$ & 10 \\
\hline
\end{tabular}

The top-level element at level 3 can be obtained from "Table III", L3 $=\{\mathrm{H} 2$, H6 $\}$

TABLE III. TOP-LEVEL ELEMENT AT LEVEL 3

\begin{tabular}{|l|l|l|l|}
\hline $\mathrm{Hi}$ & $\mathrm{R}(\mathrm{Hi})$ & $\mathrm{A}(\mathrm{Hi})$ & $\mathrm{R}(\mathrm{Hi}) \cap \mathrm{A}(\mathrm{Hi})$ \\
\hline $\mathrm{H} 2$ & 2 & $2,3,4,5,7,9,10$ & 2 \\
\hline H3 & $2,3,4,5,6,10$ & 3 & 3 \\
\hline H4 & $2,4,10$ & $3,4,5,7,9$ & 4 \\
\hline H5 & $2,4,5,6,10$ & 3,5 & 5 \\
\hline H6 & 6 & $3,5,6$ & 6 \\
\hline H7 & $2,4,7,10$ & 7,9 & 7 \\
\hline H9 & $2,4,7,9,10$ & 9 & 9 \\
\hline H10 & 2,10 & $3,4,5,7,9,10$ & 10 \\
\hline
\end{tabular}

The top-level element at level 4 can be obtained from "Table IV", L4= $\{\mathrm{H} 10\}$
TABLE IV. TOP-LEVEL ELEMENT AT LEVEL 4

\begin{tabular}{|l|l|l|l|}
\hline $\mathrm{H}_{\mathrm{i}}$ & $\mathrm{R}\left(\mathrm{H}_{\mathrm{i}}\right)$ & $\mathrm{A}\left(\mathrm{H}_{\mathrm{i}}\right)$ & $\mathrm{R}\left(\mathrm{H}_{\mathrm{i}}\right) \cap \mathrm{A}\left(\mathrm{H}_{\mathrm{i}}\right)$ \\
\hline $\mathrm{H}_{3}$ & $3,4,5,10$ & 3 & 3 \\
\hline $\mathrm{H}_{4}$ & 4,10 & $3,4,5,7,9$ & 4 \\
\hline $\mathrm{H}_{5}$ & $4,5,10$ & 3,5 & 5 \\
\hline $\mathrm{H}_{7}$ & $4,7,10$ & 7,9 & 7 \\
\hline $\mathrm{H}_{9}$ & $4,7,9,10$ & 9 & 9 \\
\hline $\mathrm{H}_{10}$ & 10 & $3,4,5,7,9,10$ & 10 \\
\hline
\end{tabular}

The top-level element at level 5 can be obtained from "Table V", $\mathrm{L}_{5=}\left\{\mathrm{H}_{4}\right\}$

TABLE V. TOP-LEVEL ELEMENT AT LEVEL 5

\begin{tabular}{|l|l|l|l|}
\hline $\mathrm{H}_{\mathrm{i}}$ & $\mathrm{R}\left(\mathrm{H}_{\mathrm{i}}\right)$ & $\mathrm{A}\left(\mathrm{H}_{\mathrm{i}}\right)$ & $\mathrm{R}\left(\mathrm{H}_{\mathrm{i}}\right) \cap \mathrm{A}\left(\mathrm{H}_{\mathrm{i}}\right)$ \\
\hline $\mathrm{H}_{3}$ & $3,4,5$ & 3 & 3 \\
\hline $\mathrm{H}_{4}$ & 4 & $3,4,5,7,9$ & 4 \\
\hline $\mathrm{H}_{5}$ & 4,5 & 3,5 & 5 \\
\hline $\mathrm{H}_{7}$ & 4,7 & 7,9 & 7 \\
\hline $\mathrm{H}_{9}$ & $4,7,9$ & 9 & 9 \\
\hline
\end{tabular}

The top-level element at level 6 can be obtained from "Table VI", $\mathrm{L}_{6=}\left\{\mathrm{H}_{5}, \mathrm{H}_{7}\right\}$

TABLE VI. TOP-LEVEL ELEMENT AT LEVEL 6

\begin{tabular}{|l|l|l|l|}
\hline $\mathrm{H}_{\mathrm{i}}$ & $\mathrm{R}\left(\mathrm{H}_{\mathrm{i}}\right)$ & $\mathrm{A}\left(\mathrm{H}_{\mathrm{i}}\right)$ & $\mathrm{R}\left(\mathrm{H}_{\mathrm{i}}\right) \cap \mathrm{A}\left(\mathrm{H}_{\mathrm{i}}\right)$ \\
\hline $\mathrm{H}_{3}$ & 3,5 & 3 & 3 \\
\hline $\mathrm{H}_{5}$ & 5 & 3,5 & 5 \\
\hline $\mathrm{H}_{7}$ & 7 & 7,9 & 7 \\
\hline $\mathrm{H}_{9}$ & 7,9 & 9 & 9 \\
\hline
\end{tabular}

The top-level element at level 7 can be obtained from "Table VII", $\mathrm{L}_{7=}\left\{\mathrm{H}_{3}, \mathrm{H}_{9}\right\}$

TABLE VII. TOP-LEVEL ELEMENT AT LEVEL 7

\begin{tabular}{|l|l|l|l|}
\hline $\mathrm{H}_{\mathrm{i}}$ & $\mathrm{R}\left(\mathrm{H}_{\mathrm{i}}\right)$ & $\mathrm{A}\left(\mathrm{H}_{\mathrm{i}}\right)$ & $\mathrm{R}\left(\mathrm{H}_{\mathrm{i}}\right) \cap \mathrm{A}\left(\mathrm{H}_{\mathrm{i}}\right)$ \\
\hline $\mathrm{H}_{3}$ & 3 & 3 & 3 \\
\hline $\mathrm{H}_{9}$ & 9 & 9 & 9 \\
\hline
\end{tabular}

To sum up, the analysis is available, $\mathrm{L} 1=\{\mathrm{H} 8\}$; $\mathrm{L} 2=\{\mathrm{H} 1\} ; \mathrm{L} 3=\{\mathrm{H} 2, \mathrm{H} 6\} ; \mathrm{L} 4=\{\mathrm{H} 10\} ; \mathrm{L} 5=\{\mathrm{H} 4\}$; $\mathrm{L} 6=\{\mathrm{H} 5, \mathrm{H} 7\} ; \mathrm{L} 7=\{\mathrm{H} 3, \mathrm{H} 9\}$.

\section{F. Set up Interpretation Structure Model}

According to the hierarchy division, the interpretation structure model of the human error system in ship collision is drawn, as shown in "Fig. 2". 


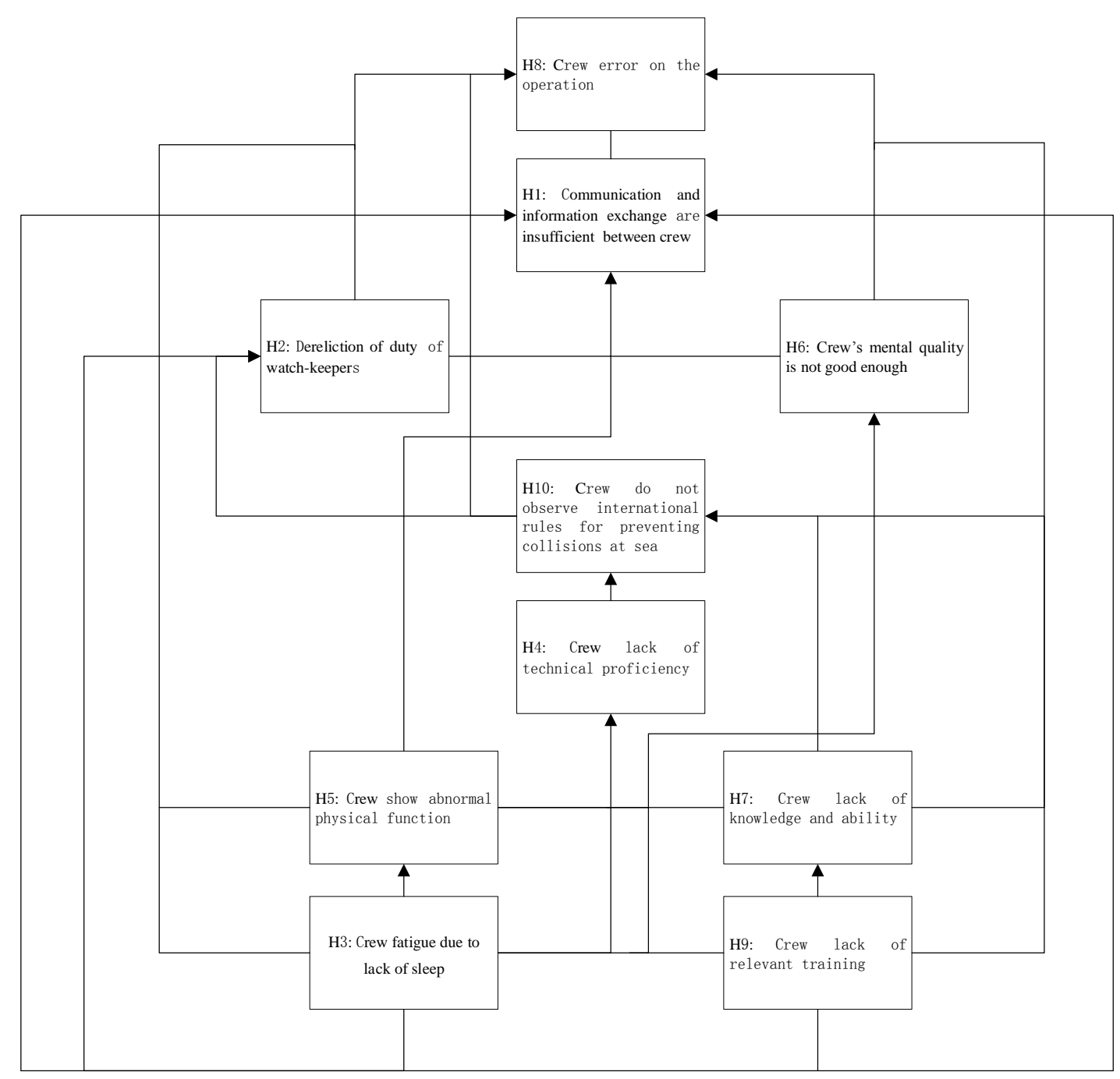

Fig. 2. Interpretation structure model of the human error system in ship collision.

\section{ANALYSIS OF THE ISM OF HUMAN ERROR FACTORS IN SHIP COLLISION}

As can be seen from the interpretation structure model in "Fig. 2", the human factor error system in ship collision is a seven-stage hierarchical structure model, which indicates the logical relationship between various factors. In view of the large hierarchy of ISM model results, level 2 is classified as surface factor, level 3 and level 4 are classified as shallow factor, level 5 and 6 are classified as middle factor, and level 7 is considered as deep factor. The hierarchical structure analysis is as follows:

\section{A. Surface Factor}

"Communication and information exchange are insufficient between crew" is the most direct factor that leads to the failure of crew operation behavior, namely the surface factor. In the process of completing a task, $80 \%$ of them is needed to cooperate with each other through communication between people, whether verbal or other means of communication such as devices. And workers on the ship who in a job or a department, must need real-time contact and signal transfer. If crew misunderstand the meanings of both sides, or two ship personnel have barriers on verbal communication, which will not perfectly convey the correct information, it is easy to cause the crew choose incorrect operation and appear error. Especially in the process of avoiding collision, there exists the problem of a ship avoiding other ships. If there is any misunderstanding in the communication, it is likely that neither party has made the collision avoidance operation, which will lead to the accident.

\section{B. Shallow Factor}

"Dereliction of duty of watch-keepers, Crew's mental quality is not good enough, Crew do not observe international rules for preventing collisions at sea" are shallow factor that causes the operation failure of the crew. Lookout post is one of the important position of ship during the voyage, lookout post staffs must always hold a telescope watching each ships, leaving or distraction in the working process are belong to the post responsibility, one meet emergencies and do not report timely to the superior may bring error pressure to other operators. Crew should have good psychological quality, cannot appear panicked state 
when meet an emergency, he must be calm in the face of problems and solve the problem. Crew's psychology can't work in loose idle state, should remain on high alert at all times, psychological negative emotions will give a negative impact on its operation behavior. Crew did not comply with the international regulations for preventing collisions at sea will bring great safety hidden trouble, such as not use radar or wrong use radar during the voyage, not issue a security alert to remind each other in the first time in the process of collision avoidance, these actions are mistakes.

\section{Middle Factor}

"Crew lack of technical proficiency, Crew show abnormal physical function, Crew lack of knowledge and ability" are middle factor that causes the operation failure of the crew. If the ship suddenly damage, such as engine or the steering gear failure, this time need skilled crew to immediately assess and maintain the machine, if crew failed to in a short period of time for inspection and maintenance, failure may be produced in the time delay. Crew body function is abnormal, here mainly refers to crew have disease, physical defects, excessive alcohol, etc., in the working status that body function is abnormal, it is hard not to cause error, so crew should have good physical quality health safety. Lacking of knowledge and ability refers to lack of professional knowledge and lead to incompetence or ignorance, knowledge levels is related to older individuals and work experience of accident, if someone have the experience of dealing with marine accident and rank position of education experience, so crew's knowledge level will more higher, can more effectively avoid operating error behavior.

\section{Deep Factor}

"Crew fatigue due to lack of sleep, Crew lack of relevant training" are deep factor that causes the operation failure of the crew. After reading many maritime collision accidents, we found that it has a large degree of relationship with crew's fatigue, the main factor of fatigue is shift work, abnormal working time, insufficient task allocation and excessive demand. If an operator is in a state of fatigue, so the probability of ship collision will greatly improve. The key to improve crew fatigue is to ensure that crew sleep, also equip with adequate staffs, normal diet, reduce administrative tasks, adjust entertainment life in relax. It is very important to train for crew regularly, including psychological quality, knowledge level, training skills, interpersonal, communication, security culture consciousness. We should take training of different subjects, improve the professional quality of the crew from all sides. If crew lacks the training system, they will lack the ability to prevent accidents, which may easily lead to maritime accidents.

\section{CONCLUSION}

Seeing the human factors of human error in a collision as a system, after reading the collision accident in recent years, the passage summarizes 10 typical human cause, set up the interpretation
Structure model of the system, draws a magnitude 7 levels hierarchical structure. From the ISM model, we can get different levels of incentives: direct factors, the shallow, middle and deep factors. Crew fatigue and lacking of training are the deep causes of human error. In order to reduce ship collision accidents, the shipping company or management personnel can focus intervention from the two aspects.

In the research of collision human error caused by human factors, is a system engineering. In the later study, researchers can compare human error caused by other factors to human error caused by human factors, or a combination of analysis, adopts other evaluation methods were analyzed, can be study further about human error cause in ship collision.

\section{REFERENCES}

[1] Fu Yuhui. Effect mechanism of human fault in accidents[J]. Journal of Dalian Maritime University, 2004, 30(3): 106-108,112.

[2] Li Lingling, Qiu Lei. Causation Analysis of Human Error Related Marine Accidents Using Apriori Algorithm[J]. Journal of Transport Information and Safety, 2014, 32(2): 110-114.

[3] Liang Kailin. Analysis on human factors in maritime traffic accident based on CREAM[D]. Daliani: Dalian Maritime University, 2014.

[4] Zhang Lili, Lv Jing, Ai Yunfei. Analyzing Human Error in Maritime Transportation in China Based on Game Theory[J]. Journal of Wuhan University of Technology: Transportation Sciense \& Engineering, 2014, 38(6): 1282-1285,1290.

[5] Catherine H, Rhona F, Kathryn M. Safety in shipping: The human element[J]. Journal of Safety Research, 2006, 37(4): 401-411.

[6] Emestos T. Human Element and Accidents in Greek Shipping[J]. The Journal of Navigation, 2010, 63: 119-127.

[7] Christine C. Human Factors and Maritime Safety[J]. The Journal of Navigation, 2011, 64: 625-632.

[8] Christine C, SALIM L, GAEL M, et al. Human and organizational factors in maritime accidents: Analysis of Collisions at sea using the HFACS[J]. Accident Analysis and Prevention, 2013, 59: 26-37.

[9] Muhammad J and Ingrid B. Common patterns in aggregated accident analysis charts from human fatigue-related groundings and collisions at sea[J]. Maritime Policy \& Managfement, 2015, 42(2): 186-206.

[10] Li Guogang, Kong Jing. Estabish logistics reachable matrix based on the interpretation of the ISM model[J]. Decision Reference, 2013(19):42-44.

[11] Li Naiwen, Xu Menghong, NIU Lixia. Study on Factors Influencing Miners Habitual Violation Behavior Based on ISM and AHP[J]. China Safety Sciense Journal, 2012, 22(8): 22-28. 